\title{
Disproportionate Supression of Dehydroepiandrosterone Sulfate (DHEAS) in Treated Patients with Congenital Adrenal Hyperplasia due to 21-Hydroxylase Deficiency
}

\author{
IRAJ REZVANI, ${ }^{(34)}$ LUIGI R. GARIBALDI, ANGELO M. DIGEORGE, AND HENRY G. ARTMAN \\ Department of Pediatrics, Temple University School of Medicine and Section of Endocrine and Metabolic Disorders at \\ St. Christopher's Hospital for Children, Philadelphia, Pennsylvania, USA
}

\begin{abstract}
Summary
Serum concentrations of dehydroepiandrosterone sulfate (DHEAS) were measured in 28 patients (18 females, 10 males) with congenital adrenal hyperplasia due to 21-hydroxylase deficiency who were treated with oral hydrocortisone (non-salt losers) or hydrocortisone and 9- $\alpha$-fluorohydrocortisone (salt-losers). Adequacy of therapy was assessed by clinical findings, determination of bone age, urinary excretion of 17-ketosteroids, and serum concentration of 17-hydroxyprogesterone. These allowed the separation of patients into three groups: poorly controlled, adequately controlled and overtreated. Individual values for serum levels of DHEAS were compared to mean normal values for age. In the adequately controlled and overtreated patients, mean serum concentrations of DHEAS were significantly lower than normal values for age $(P<0.05)$. In the poorly treated patients, the mean serum concentration of DHEAS was not significantly different from normal values for age $(P=0.50)$.

These data indicate that the serum concentration of DHEAS is overly suppressed in treated patients with congenital adrenal hyperplasia due to 21-hydroxylase deficiency. This finding suggests that measurement of the serum levels of DHEAS has limited value in assessing the adequacy of therapy in this disease.
\end{abstract}

\section{Abbreviations}

CAH, congenital adrenal hyperplasia due to 21-hydroxylase deficiency

DHEAS, dehydroepiandrosterone sulfate

17-OHP, 17-hydroxyprogesterone

SDS, standard deviation score

A major goal in long term management of patients with congenital adrenal hyperplasia due to 21-hydroxylase deficiency (CAH) is to suppress the effects of excessive adrenal androgens. The adequacy of suppression has been traditionally monitored by periodic measurement of 24-h urinary excretion of 17-ketosteroids and pregnanetriol. The reliability of these assays, however, is hampered by inaccuracies in collection of 24-h urine specimens. A suitable compound that can be measured in blood, therefore, has been searched for by several investigators. Dehydroepiandrosterone sulfate (DHEAS), the most abundant adrenal androgen, seems to be a likely candidate for this purpose because it is almost exclusively synthesized by the adrenal glands $(17,19)$. Moreover, as DHEAS has a long half-life $(24,26)$, its concentration in serum is less susceptible to diurnal variations (25).

Recent studies have demonstrated that serum levels of DHEAS are increased in patients with untreated CAH $(11,15,23)$; however, data on the serum concentration of the hormone during therapy are very limited. Serum levels of DHEAS did not increase in six patients with $\mathrm{CAH}$ when therapy was discontinued for 3 days (33). Golden et al. (11) found elevated levels of serum DHEAS in patients with CAH only when they were overtly undertreated, but values for serum levels of DHEAS were not correlated with the age of the patients. Because secretion of DHEAS is age dependent $(8,15,23)$, its role in the management of patients with $\mathrm{CAH}$ cannot be quantitated unless appropriate age-matched control values are applied. The purpose of this study was to determine the usefulness of serum concentration of DHEAS for monitoring therapy in patients with CAH and to compare serum levels of the hormone to those obtained in age-matched control subjects.

\section{MATERIALS AND METHODS}

Twenty-eight patients, 18 females and 10 males with $\mathrm{CAH}$ (Table 1), were followed as outpatients at 3-6 month intervals. Congenital adrenal hyperplasia had been diagnosed in each case at least 2 years before this study. All patients were being treated with oral hydrocortisone twice daily at a mean dose of $17.9 \mathrm{mg}$ / $\mathrm{m}^{2} /$ day; 9- $\alpha$-fluorohydrocortisone $(50-200 \mu \mathrm{g} /$ day) was added only if the patient was a "salt loser." The dose of medication had remained unchanged for at least 1 year before the study.

Adequacy of treatment was assessed by the following criteria:

(1) normal linear growth;

(2) normal bone age and normal rate of advancement of bone age;

(3) no evidence of ongoing inappropriate virilization such as premature appearance of pubic hair or phallic or clitoral enlargement;

(4) urinary 17 ketosteroids at or below age-related upper limits (14);

(5) serum concentration of 17-hydroxyprogesterone (17-OHP) below $500 \mathrm{ng} / \mathrm{dl}$ (one patient with a serum level of 17-OHP of $757 \mathrm{ng} /$ dl was considered adequately controlled because the rest of the criteria were fulfilled); and

(6) normal testicular size for age or regular menses in adolescent male and female subjects, respectively.

On the basis of these parameters, we separated the patients into three groups: (A) poorly controlled; (B) adequately controlled; and (C) overtreated.

Serum samples for determination of DHEAS and 17-hydroxyprogesterone were obtained during clinic visits, which occurred between $0900-1600 \mathrm{hs}$. The morning doses of hydrocortisone and of 9- $\alpha$-fluorohydrocortisone (when required) had been administered at approximately $0730-0830 \mathrm{~h}$.

Serum samples for determination of DHEAS were also obtained from 107 control subjects ( 64 males, 43 females, 2-23 years of age) referred to the Endocrine Clinic, who had neither an adrenal disorder nor an abnormality of pubertal development.

Serum concentrations of DHEAS were measured by radioimmunoassay (5). The coefficient of variation within the assay was less than 3\%; the interassay coefficient of variation ranged from 
Table 1. Clinical and laboratory data on 28 patients with congenital adrenal hyperplasia due to 21 hydroxylase deficiency ${ }^{1}$

\begin{tabular}{|c|c|c|c|c|c|c|c|c|c|}
\hline \multicolumn{10}{|c|}{ Group A (poorly controlled) } \\
\hline \multirow[b]{2}{*}{ Patient/Sex } & & \multirow[b]{2}{*}{ Age (Years) } & \multirow[b]{2}{*}{$\begin{array}{l}\text { Salt } \\
\text { loser }\end{array}$} & \multirow{2}{*}{$\begin{array}{l}\text { Dose of hydro- } \\
\text { cortisone (mg/ } \\
\mathrm{m}^{2} / \text { day) }\end{array}$} & \multicolumn{2}{|c|}{ Urine } & \multicolumn{3}{|c|}{ Serum } \\
\hline & & & & & $17 \mathrm{KS}$ & PT & $\begin{array}{l}17 \text { OHP } \\
(\mathrm{ng} / \mathrm{dl})\end{array}$ & $\begin{array}{l}\text { DHEAS } \\
(\mu \mathrm{g} / \mathrm{dl})\end{array}$ & DHEAS-SDS \\
\hline 1 & $\mathrm{~F}$ & 9.9 & Yes & 26.7 & \multicolumn{2}{|c|}{ (mg/day) } & 2750 & 105 & +2.14 \\
\hline 2 & $\mathrm{~F}$ & 10.3 & Yes & 26.2 & 9.2 & 11 & 9150 & 41 & -0.67 \\
\hline 3 & $\mathrm{~F}$ & 11.1 & No & 19.4 & 21.1 & 22 & 1717 & 56 & -0.13 \\
\hline 4 & $\mathrm{M}$ & 12.3 & No & 12.4 & 12 & & 1120 & 123 & +0.57 \\
\hline 5 & $M$ & 14.4 & No & 28.6 & & & 18000 & 29 & -1.53 \\
\hline 6 & M & 14.9 & Yes & 11.8 & 25.2 & 31 & 4806 & 102 & -0.50 \\
\hline 7 & $\mathrm{~F}$ & 14.9 & Yes & 15.4 & 74.6 & 22 & 16000 & 167 & +0.41 \\
\hline 8 & $\mathrm{~F}$ & 14.9 & No & 18.0 & 22.1 & 9 & 7720 & 252 & +1.61 \\
\hline 9 & $\mathrm{M}$ & 15.3 & Yes & 18.0 & 23.2 & 23 & 3800 & 142 & +0.06 \\
\hline 10 & $\mathrm{~F}$ & 15.5 & Yes & 14.5 & 16.6 & 22 & 6500 & 16 & -1.72 \\
\hline 11 & $\mathbf{M}$ & 16.4 & No & 18.7 & 25.9 & 12 & 997 & 246 & +0.91 \\
\hline Mean \pm S.D. & & $13.6 \pm 2.3$ & $55 \%$ & $19.1 \pm 5.8$ & $25.5 \pm 19.2$ & $19 \pm 7.6$ & $6596 \pm 5807$ & $116 \pm 81$ & $+0.102 \pm 1.2$ \\
\hline \multicolumn{10}{|c|}{ Group B (adequately controlled) } \\
\hline 1 & $\mathbf{M}$ & 2.3 & Yes & 20.8 & & & 410 & 17 & +1.55 \\
\hline 2 & $\mathbf{M}$ & 2.5 & Yes & 19.2 & & & 230 & 2 & -0.65 \\
\hline 3 & $F$ & 4.2 & Yes & 15.6 & 2.8 & 1.3 & 757 & 14 & +0.18 \\
\hline 4 & $\mathrm{~F}$ & 8.2 & No & 16.7 & 5.0 & 1.1 & 308 & 15 & -0.83 \\
\hline 5 & $\mathrm{~F}$ & 9.1 & Yes & 15.0 & 2.6 & 0.3 & 46 & 6 & -1.13 \\
\hline 6 & $\mathbf{M}$ & 11.4 & No & 20.0 & & & 255 & 54 & -0.20 \\
\hline 7 & $\mathrm{~F}$ & 14.0 & No & 13.3 & 2.9 & 4.4 & 440 & 41 & -1.37 \\
\hline 8 & $\mathrm{~F}$ & 14.7 & Yes & 18.5 & & & 237 & 15 & -1.73 \\
\hline 9 & $\mathrm{~F}$ & 17.0 & Yes & 22.5 & 7.2 & 0.6 & 78 & 11 & -2.88 \\
\hline 10 & $\mathrm{~F}$ & 22 & No & 18.2 & 2.8 & 0.7 & 162 & 76 & -1.83 \\
\hline Mean \pm S.D. & & $10.5 \pm 6.5$ & $60 \%$ & $18 \pm 2.8$ & $3.9 \pm 1.9$ & $1.4 \pm 1.5$ & $292 \pm 206$ & $25 \pm 24$ & $-0.89 \pm 1.22$ \\
\hline \multicolumn{10}{|c|}{ Group C (overtreated) } \\
\hline 1 & $\mathrm{~F}$ & 2.6 & Yes & 18.5 & 1.4 & 0.1 & 9.1 & $<4$ & -0.64 \\
\hline 2 & $\mathrm{~F}$ & 3.9 & Yes & 16.7 & 0.5 & 0.3 & 14 & $<4$ & -0.60 \\
\hline 3 & $\mathbf{M}$ & 4.0 & Yes & 13.3 & 1.5 & 0.1 & 8 & $<4$ & -0.60 \\
\hline 4 & $\mathrm{~F}$ & 6.7 & Yes & 23.0 & 2.1 & $<0.05$ & & 6 & -1.12 \\
\hline 5 & $\mathbf{M}$ & 6.8 & Yes & 11.8 & 5.4 & 0.07 & 9 & $<4$ & -1.42 \\
\hline 6 & $\mathrm{~F}$ & 7.0 & Yes & 15.6 & 0.8 & $<0.05$ & 23 & $<4$ & -1.27 \\
\hline 7 & $\mathrm{~F}$ & 8 & Yes & 12.5 & 2.4 & $<0.05$ & 10.5 & 6 & -1.13 \\
\hline Mean \pm S.D. & & $5.5 \pm 2.0$ & $100 \%$ & $15.9 \pm 4.0$ & $2.0 \pm 1.6$ & $0.1 \pm 0.08$ & $12.2 \pm 5.6$ & & $-0.96 \pm 0.3$ \\
\hline
\end{tabular}

' Abbreviations: $17 \mathrm{KS}, 17$ ketosteroids; PT, pregnanetriol; $17 \mathrm{OHP}, 17$ hydroxyprogesterone; DHEAS, dehydroepiandrosterone sulfate; and SDS, standard deviation score.

6\% (at a DHEAS concentration of $288 \mu \mathrm{g} / \mathrm{dl}$ to $10.6 \%$ (at a DHEAS concentration of $36 \mu \mathrm{g} / \mathrm{dl}$ ). Values less than $4 \mu \mathrm{g} / \mathrm{dl}$ were below the sensitivity of the assay.

Serum levels of 17-OHP were measured by radioimmunoassay (1). The coefficient of variation within the assay was less than $3 \%$; the coefficient of variation between the assays was $15.5 \%$ when the mean level of 17-OHP was $62 \mathrm{ng} / \mathrm{dl}$.

Twenty-four $\mathrm{h}$ urine samples were collected at home, generally the day before or occasionally within a few days before the visit. Urinary concentrations of 17 -ketosteroids (10) and preganetriol (3) were measured by conventional methods.

Statistical analysis. Because serum concentration of DHEAS normally changes with age, the values from individual patients were compared to the mean of serum DHEAS from age-matched control subjects. To allow for age differences in the three groups of patients, we calculated the standard deviation score (SDS) for each patient from the formula $\operatorname{SDS}=(x-\bar{x}) \div$ S.D. where $x$ is the value for the patient, $\bar{x}$ and S.D. are the mean and standard deviation, respectively, for the age-matched control subjects (4, 31 ). In this way, standard deviation scores from patients of all ages can be grouped together and averaged. By using this formula, the mean SDS value for any normal population is zero regardless of age. The $P$ value for SDS was calculated by using two-way analysis of the variance (9). Linear regression analysis was em- ployed to test for correlation between serum levels of DHEAS and age.

\section{RESULTS}

The pertinent clinical and laboratory data of 28 patients with $\mathrm{CAH}$ are listed in Table 1. Patients in poor control (Group A) and adequate control (Group B) were comparable for mean age and prevalence of "salt-losers," whereas children who were overtreated (Group C) were younger and all had the "salt-losing" form of CAH. The sex ratio and the mean daily dose of hydrocortisone were comparable in the three groups. Mean serum concentrations of DHEAS were significantly lower in patients classified as adequately controlled (Group B, $25 \pm 24 \mu \mathrm{g} / \mathrm{dl}$ ) than in patients in poor control (Group A, $116 \pm 81 \mu \mathrm{g} / \mathrm{dl}, P<0.01$ ).

In Figure 1, serum levels of DHEAS from individual patients were compared to those obtained in age-matched control subjects. Serum concentrations of DHEAS were low for the degree of control of the disease, as they were within I S.D. of the normal mean in 9 of 11 poorly controlled patients (Group A), below 1 S.D. in 6 of 10 adequately controlled (Group B), and overly suppressed in overtreated patients (Group C). Similar results were obtained when serum concentrations of DHEAS were expressed as standard deviation scores (SDS) for age (Table 1). DHEAS-SDS values 


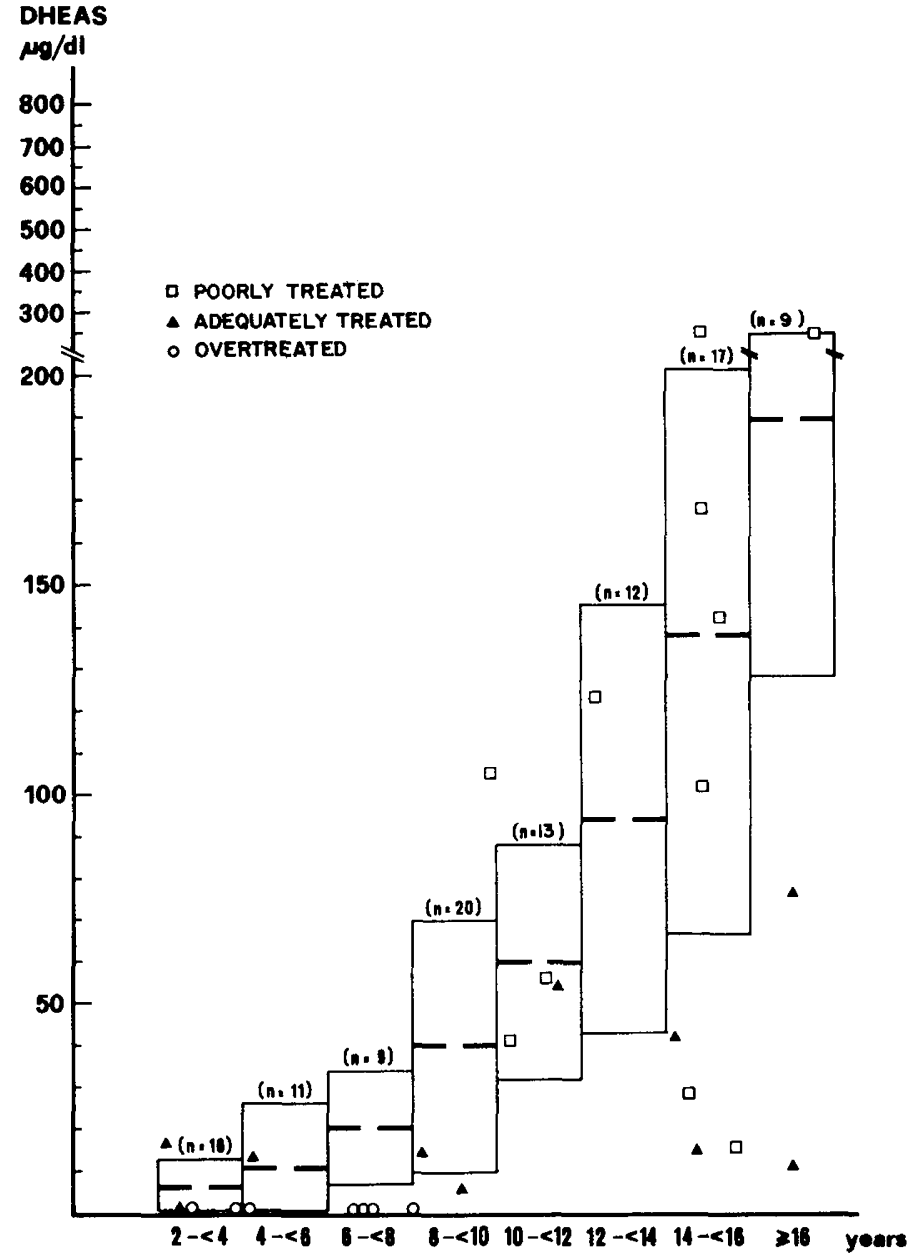

Fig. 1. Serum concentrations of dehydroepiandrosterone sulfate (DHEAS) in 107 normal subjects and 28 patients with congenital adrenal hyperplasia. The number above each bar denotes the number of normal subjects in each age group. The vertical bars denote \pm 1 S.D. from the mean. The horizontal lines show the mean values.

were not significantly different from zero (i.e., the mean for normal age-matched subjects) in poorly controlled patients (Group A, $P=0.50$ ), whereas in adequately treated patients with CAH (Group B) DHEAS-SDS values were significantly lower than the mean for the control population $(P<0.05)$. The mean DHEAS-SDS in overtreated patients was also significantly lower than zero; this is, however, a mere approximation because most of the values in this group of patients were below the sensitivity of the assay.

The correlation between serum concentrations of DHEAS and age is shown in Figure 2. As expected, serum concentrations of DHEAS correlated significantly with age in normal subjects from $2-18$ years of age $(r=0.78, P<0.001)$. The correlation was still significant in adequately controlled patients with CAH ( $r=0.64$, $P<0.05$ ) but the slope of the regression line in this group was significantly less steep $(P<0.001)$ than that obtained in normal subjects, thus emphasizing again the excessive suppression of serum DHEAS in adequately treated patients with CAH. In poorly controlled patients with $\mathrm{CAH}$, the correlation between age and serum DHEAS concentration was not significant $(r=0.43, P$ $<0.10$ ).

\section{RESULTS}

We have examined serum DHEAS concentrations in 28 patients with CAH due to 21-hydroxylase deficiency and found them to be inappropriately low for the degree of control of the disease.
Serum levels of DHEAS sere significantly below the normal values for age in patients who were believed to be in adequate control, whereas they were within normal limits for age in most of the patients in poor control.

The criteria used in our study to determine the adequacy. of therapy were too crude to assess optimal treatment. One may argue that the low levels of DHEAS found in the adequately controlled patients may simply be due to a mild degree of overtreatment not detected by our insensitive methods. This, however, does not seem to be the case in-as-much as serum levels of 17 OHP were above the upper limit of normal $[200 \mathrm{ng} / \mathrm{dl}(13)]$ in most of these subjects.

Golden et al. (11) also measured serum levels of DHEAS during therapy in 18 patients with CAH and found elevated levels only in those patients who were grossly undertreated. Oversuppression of serum levels of DHEAS, however, cannot be discerned in this report because these authors considered serum levels of DHEAS of less than $100 / \mu \mathrm{g} / \mathrm{dl}$ to be normal regardless of the patients' age and stage of pubertal development.

The serum concentrations of other $\Delta_{5}$ androgens have been found to be low in patients with $\mathrm{CAH}$ treated with glucocorticoids. Korth-Schutz et al. (16) and Anderson (2) found low levels of serum dehydroepiandrosterone in both optimally and poorly controlled patients with $\mathrm{CAH}$ and concluded that dehydroepiandrosterone is not a good index of control in this condition. In another study of 21 patients who were treated for $\mathrm{CAH}$ (18), pregnenolone and 17-hydroxypregnenolone increased only after repeated injections of repository ACTH, but not after short term synthetic ACTH stimulation. In contrast to $\Delta_{5}$ compounds, serum concentrations of some adrenal $\Delta_{4}$ compounds such as 17-OHP (33), androstenedione $(6,16)$, and testosterone $(6,27)$, increase rapidly when treatment is inadequate and decrease to normal levels when therapy is optimal; thus, the ratios of dehydroepiandrosterone or DHEAS to 17-OHP, androstenedione or testosterone, respectively, are reduced below normal values in patients with $\mathrm{CAH}$ who are well controlled.

The reason for disproportionately low levels of serum DHEAS in treated patients with CAH remains speculative. Dissociation between the rate of secretion of adrenal androgens and glucocor-

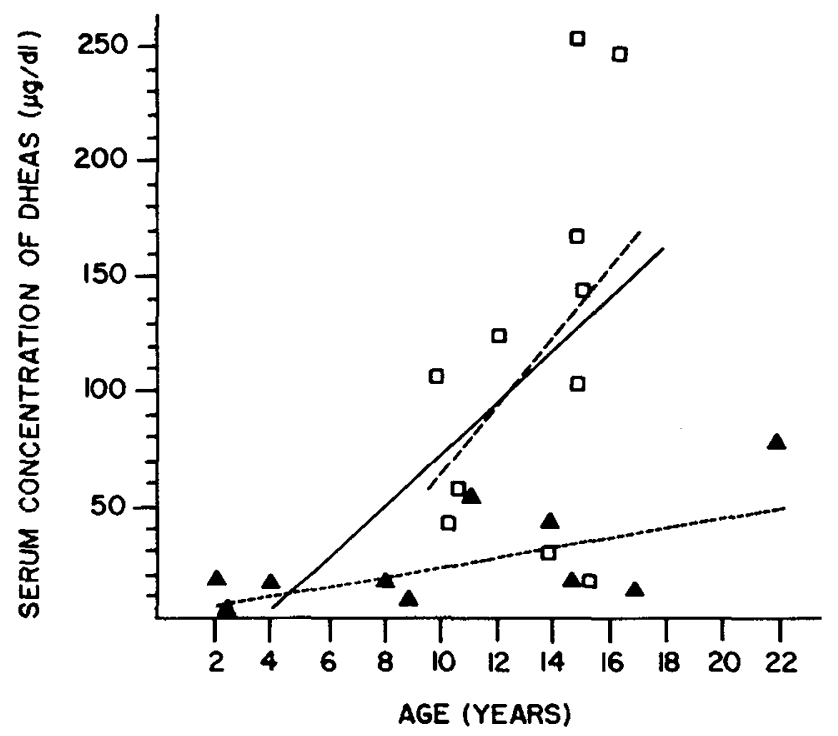

Fig. 2. Correlation of serum concentration of dehydroepiandrosterone sulfate (DHEAS) with age. ( - ), Normal subjects ( $\mathrm{y}=11.5 \mathrm{x}-45, r=$ $0.78, P<0.01)$. Individual values $(n=103)$ are not plotted to avoid crowding of the figure. (A- $\mathbf{\Delta})$, Patients with congenital adrenal hyperplasia due to 21-hydroxylase deficiency $(\mathrm{CAH})$ in adequate control $(\mathrm{y}=$ $2.4 \mathrm{x}+0.2, r=0.64, P<0.05$ ). ( $\square-\square$ ), Patients with congenital adrenal hyperplasia due to 21 -hydroxylase deficiency $(\mathrm{CAH})$ in poor control $(\mathrm{y}=$ $15.2 \mathrm{x}-90, r=0.42, P<0.1$ ). 
ticoids has been observed in various pathologic $(7,29)$ and experimental (20) conditions, as well as during normal development $(21,23,28)$. In fact, increase of the DHEAS/cortisol ratio is the hallmark of adrenarche in normal children $(22,32)$. These observations have led to the hypothesis that adrenal androgens may be controlled by another pituitary hormone in addition to ACTH $(12,20,30)$. It is conceivable that this putative adrenal androgenstimulating hormone is suppressed more readily than ACTH by exogenous cortisol in patients treated for $\mathrm{CAH}$, resulting in a far greater decrease in serum levels of DHEAS than of 17-OHP. The existence of such a hormone, however, has been challenged and alternative explanations have been suggested $(2,22)$.

The oversuppression of serum DHEAS observed in this study limits the usefulness of the assay in evaluating the adequacy of therapy in patients with CAH. Although high levels of serum DHEAS indicate that treatment is grossly inadequate, normal or low values of serum DHEAS do not reflect necessarily adequacy of therapy.

The physiologic significance of this disproportionate suppression of DHEAS remains unclear at this time and merits further study.

\section{REFERENCES AND NOTES}

1. Abraham, G. E., Swerdloff, R. S., Tulchinsky, D., Hooper, K., and Odell, W. D.: Radioimmunoassay of plasma 17-hydroxyprogesterone. J. Clin. Endocrinol. Metab., 33: 42 (1971).

2. Anderson, D. C.: The adrenal androgen-stimulating hormone does not exist. Lancet, 2: 454 (1980).

3. Bongiovanni, A. M. and Eberlein, W. R.: Critical analysis of methods for measurement of pregnane-3-alpha, 20-alpha triol in human urine. Analyt. Chem., 30: 388 (1958).

4. Brook, C. G. D., Zachman, M., Prader, A., and Murset, G.: Experience with long term therapy in congenital adrenal hyperplasia. J. Pediatr., 85: 12 (1974).

5. Buster, J. E. and Abraham, G. E.: Radioimmunoassay of plasma dehydroepiandrosterone sulfate. Analyt. Lett., 5: 543 (1972).

6. Cavallo, A., Corn, C., Bryan, G. T., and Meyers, W. J.: The use of plasma androstenedione in monitoring therapy in patients with congenital adrenal hyperplasia. J. Pediatr., 95: 33 (1979).

7. Cutler, G. B., Jr., Davis, S. E., Johnsonbaugh, R. E., and Loriaux, D. L.: Dissociation of cortisol and adrenal secretion in patients with secondary adrenal insufficiency. J. Clin. Endocrinol. Metab, 49: 604 (1979).

8. DePeretti, E. and Forest, M. G.: Pattern of plasma dehydroepiandrosterone sulfate levels in humans from birth to adulthood: evidence for testicular production. J. Clin. Endocrinol. Metab., 47: 572 (1978).

9. Dixon, W. J. and Massay, F. J.: Introduction to statistical analysis. p. 175 (McGraw-Hill, New York, New York 1969).

10. Drekter, I. J., Heisler, A., Scism, G. R., Stern, S., Pearson, S., and McGavack, T. H.: The determination of urinary steroids: I. The preparation of pigment-free extracts and a simplified procedure for estimation of total 17 ketosteroids. J. Clin. Endocrinol. Metab., 12: 55 (1952).

11. Golden, M. P., Lippe, B. M., Kaplan, S. A., Lavin, N., and Slavin, J.: Management of congenital adrenal hyperplasia using serum dehydroepiandrosterone sulfate and 17-hydroxyprogesterone concentrations. Pediatrics, 61: 867 (1978).

12. Grumbach, M. M., Richards, G. E., Conte, F. A., and Kaplan, S. L.: Disorders of adrenal function and puberty: An assessment of the role of the adrenal cortex in normal and abnormal puberty in man and evidence for an ACTHlike pituitary adrenal androgen stimulating hormone. In V. H. T. James, M. Serio, G. Giusti, and L. Martini (eds). The Endocrine Function of the Human Adrenal Cortex, Serono Symposia, p. 583 (Academic Press, New York, New York 1978).

13. Hughes, I. A., and Winter, J. S. D.: The application of serum $17 \mathrm{OH}$-progesterone radioimmunoassay to the diagnosis and management of congenital adrenal hyperplasia. J. Pediatr., 88: 766 (1976).

14. Kirkland, R. T., Keenan, B. S., Holcombe, J. H., Kirkland, J. L., and Clayton, G. W.: The effect of therapy on mature height in congenital adrenal hyperplasia. J. Clin. Endocrinol. Metab., 47: 1320 (1978).

15. Korth-Schutz, S. Levine, L. S., and New, M. L.: Dehydroepiandrosterone sulfate (DS) levels, a rapid test for abnormal adrenal androgen secretion. J. Clin. Endocrinol. Metab., 42: 1005 (1976).

16. Korth-Schutz, S., Virdis, R., Saenger, P., Chow, D. M., Levine, L. S., and New, M. I.: Serum androgens as a continuing index of adequacy of treatment of congenital adrenal hyperplasia. J. Clin. Endocrinol. Metab., 46: 452 (1978).

17. Laatikainen, T., Laitinen, E. A., and Vihko, R.: Secretion of free and sulfateconjugated neutral steroids by the human testis. Effect of administration of human chorionic gonadotropin. J. Clin. Endocrinol. Metab., 32: 59 (1971).

18. McKenna, T. J., Jennings, A. S., Liddle, G. W., and Burr, M. I.: Pregnenolone, 17-OH-pregnenolone and testosterone in plasma of patients with congenital adrenal hyperplasia. J. Clin. Endocrinol. Metab., 42: 918 (1976).

19. Nieschlag, E., Loriaux, D. L., Ruder, H. J., Zucker, I. R., Kirschner, M. A., and Lipsett, M. B.: The secretion of dehydroepiandrosterone and dehydroepiandrosterone sulfate in man. J. Endocrinol., 57: 123 (1973).

20. Parker, L., and Odell, W.: Evidence for existence of cortical androgen stimulating hormone. Am. J. Physiol., 236 (6): E616 (1979).

21. Parker, L. N., Sack, J., Fisher, D. A., and Odell, W. O.: The adrenarche: Prolactin, gonadotropins, adrenal androgens and cortisol. J. Clin. Endocrinol. Metab., 46: 396 (1978)

22. Rich, B. H., Rosenfield, R. L., Lucky, A. W., Helke, J. C., and Otto, P.: Adrenarche: Changing adrenal response to adrenocorticotropin. J. Clin. Endocrinol. Metab., 52: 1129 (1981).

23. Reiter, E. O., Fuldauer, V. G., and Root, A. W.: Secretion of the adrenal androgen, dehydroepiandrosterone sulfate, during normal infancy, childhood, and adolescence, in sick infants and in children with endocrinologic abnormalities. J. Pediatr., 90: 766 (1977).

24. Rosenfeld, R. S., Hellman, L., and Gallagher, T. F.: Metabolism and interconversion of dehydroisoandrosterone and dehydroisoandrosterone sulfate. J. Clin. Endocrinol. Metab., 35: 187 (1972).

25. Rosenfeld, R. S., Rosenberg, B. J., Fukushima, D. K., and Hellman, L.: 24 hour secretory pattern of dehydroisoandrosterone and dehydroisoandrosterone sulfate. J. Clin. Endocrinol. Metab., 40: 850 (1975).

26. Sanberg, E., Gurpide, E., and Lieberman, S.: Quantitative studies on the metabolism of dehydroisoandrosterone sulfate. Biochemistry, 3: 1256 (1964)

27. Soloman, I. L., and Scheon, E. J.: Blood testosterone values in patients with congenital virilizing adrenal hyperplasia. J. Clin. Endocrinol. Metab., 40: 355 (1975).

28. Talbot, N. B.: The adrenal gland in health and disease. Panel discussion. Pediatrics, 3: 515 (1949).

29. Talbot, N. B., Albright, F., Saltzman, A. H., Zygmuntowicz, A. S., and Wixon, R.: The excretion of 11-oxycorticosteroid-like substances by normal and abnormal subjects. J. Clin. Endocrinol., 7: 331 (1947).

30. Talbot, N. B., Sobel, E. H., McArthur, J. W., and Crawford, J. D.: Functional endocrinology from birth through adolescence. p. 158 (Harvard University Press, Cambridge, Massachusetts 1952).

31. Tanner, J. M., Whitehouse, R. H., Hughes, P. C. R., and Vance, F. P.: Effect of human growth hormone treatment for 1 to 7 years on growth of 100 children, with growth hormone deficiency, low birth weights, inherited smallness, Turner's syndrome and other complaints. Arch. Dis. Child., 46: 745 (1971).

32. Warne, G. L., Carter, J. N., Faiman, C., Reyes, F. I., and Winter, J. S. D.: The relationship of adrenal androgens to the secretory patterns for cortisol, prolactin and growth hormone during early puberty. Pediatr. Res., 13: 211 (1979).

33. Zipf, W. B., Bacon, G. E., and Kelch, R. P.: Hormonal and clinical responses to prednisone treatment in adolescents with congenital adrenal hyperplasia. Horm. Res., 12: 206 (1980).

34. Requests for reprints should be addressed to: Dr. Iraj Rezvani, St Christopher's Hospital for Children, 2600 North Lawrence Street, Philadelphia, PA. 19133.

35. This research was supported in part by General Clinical Research Center Grant \#RR-75

36. Received for publication February 24, 1982.

37. Accepted for publication March 21, 1982. 